\title{
A Probable Case of Incomplete Trisomy of a Chromosome of the I3-I5 Group
}

\author{
J. ISHMAEL and K. M. LAURENCE \\ From the Department of Paediatric Pathology, Welsh National School of Medicine, Llandough Hospital, \\ Penarth, Glamorgan
}

It is now recognized that the presence of a portion of an extra chromosome may be associated with some of the features characteristic of one of the autosomal trisomic conditions (Patau, Therman, Inhorn, Smith, and Ruess, I96I ; Patau, Therman, Smith, Inhorn, and Picken, 1961; Zellweger, Mikamo, and Abbo, 1962; Gustavson, Hagberg, Finley, and Finley, 1962; Dent, Edwards, and Delhanty, 1963). The present case probably represents such an incomplete trisomy, where there appears to be an extra chromosome that does not fit readily into any of the accepted groups and in which the clinical picture is not entirely typical of any of the recognized trisomy syndromes. As the recording of detailed cytological and clinical data in such cases may be of value in the elucidation of possible specific effects of different chromosome regions, the following case is presented.

\section{Case Report}

This was the first child of intelligent parents: the father, a machine operator aged 30 years at the birth of the infant, has since died of a coronary thrombosis, and the mother, aged 22 years, is apparently healthy. Pregnancy was uneventful but went 18 days beyond the expected date of delivery before being terminated on July 10, 1963, by an artificial rupture of the membranes after a medical induction had failed. Forceps extraction of the head was carried out because of foetal distress during the second stage.

The male infant (weight $3,180 \mathrm{~g}$.) breathed almost immediately. He had an imperforate anus and was transferred to the Department of Child Health, Welsh National School of Medicine, at 6 hours. He had a somewhat long and narrow head, with a biparietal diameter of $9.2 \mathrm{~cm}$. and an anterior posterior of $13.5 \mathrm{~cm}$. but a normal circumference $(38 \mathrm{~cm}$.). The fontanelles were normal in size and tension. The eyes were small but showed no colobomata and the palpebral fissure sloped downwards and outwards (Fig. I). There was well-marked micrognathos and the ears, both low set,

Received November 6, 1964 the right more severely, were thick and had irregular accessory auricles $0.5 \mathrm{~cm}$. in length (Fig. 2). The î cardiovascular and respiratory systems appeared normal i and the abdomen was full but not distended. Penis $\vec{\omega}$ was small and was situated partially within the scrotum $\sigma$ (Fig. 3) in which only the left testis could be palpated. 울 The prominent median raphe was present where the anus should have been. A bulge was noted in this $c$ region when the child was crying and an anal reflex was thought to be present. The limbs showed no abnormalities but both hands showed transverse palmar creases.

On the day following delivery (July II) he passed meconium per urethra and appeared 'cerebral' with occasional fits. A transverse colostomy was established which appeared to be working well. On July 17 the fits were still occurring and he was vomiting bilestained mucus. Ten days later there was a sudden $\stackrel{\mathbb{D}}{\mathbb{2}}$

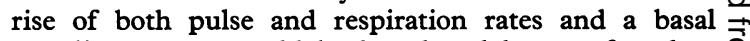
systolic murmur could be heard and he was found to $\bigcirc$ have bronchopneumonia. A large tumour was felt in the left subcostal region. His condition steadily deteriorated with a progressive upset of the electrolytes and he died on July 30 , aged 20 days.

At necropsy carried out 8 hours after death, apart from oedema of the orbits, some hypertrophy of the breasts, and the colostomy, the external features were those already described. The lungs showed circum- $\delta$ scribed areas of consolidation in the right lower lobe, found on microscopy to be due to infarction with pneumonia. The heart was anatomically normal, though there was a moderate amount of right-sided $\frac{D}{2}$ dilatation and slight ventricular hypertrophy. The ductus arteriosus was closed. The uvula was bifid N but the soft palate was otherwise complete (Fig. 4).

The distal loop of the large intestine was progressively $N$ dilated and ended blindly about $2 \mathrm{~cm}$. from the anal ్ㅣㅇ skin, a well-marked recto-urethral fistula being present. The right kidney and ureter were absent. The left kidney, grossly enlarged (weight $73 \mathrm{~g}$.), was infarcted $\stackrel{\circ}{C}$ together with its associated suprarenal gland. The $₫$ left renal vein and most of the inferior vena cava were? distended with antemortem thrombus. The right 0 suprarenal gland, though congested, was normal. The right testis was situated in the scrotum, the left in the inguinal canal. Both showed the typical infantile 


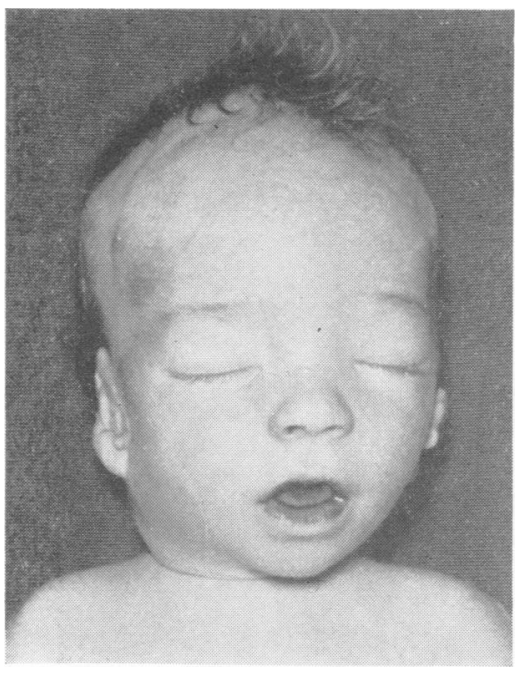

Fig. I. Appearance of the patient at necropsy, with the palpebral fissures sloping downwards and outwards.

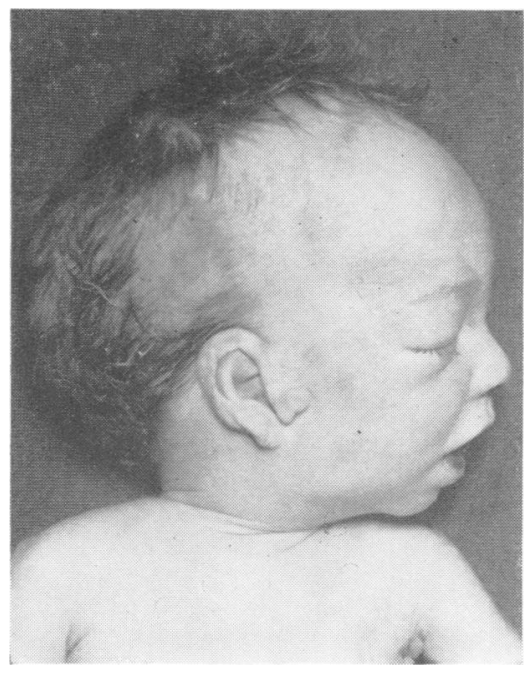

Fis. 2. Side view of the head at necropsy showing the micrognathos and the abnormal ear with its accessory auricle.

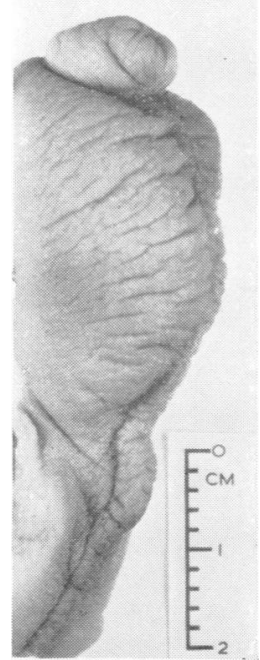

FIG. 3. Excised external genitalia showing the small penis which is partially situated within the scrotum. The prominent median raphe is also shown.

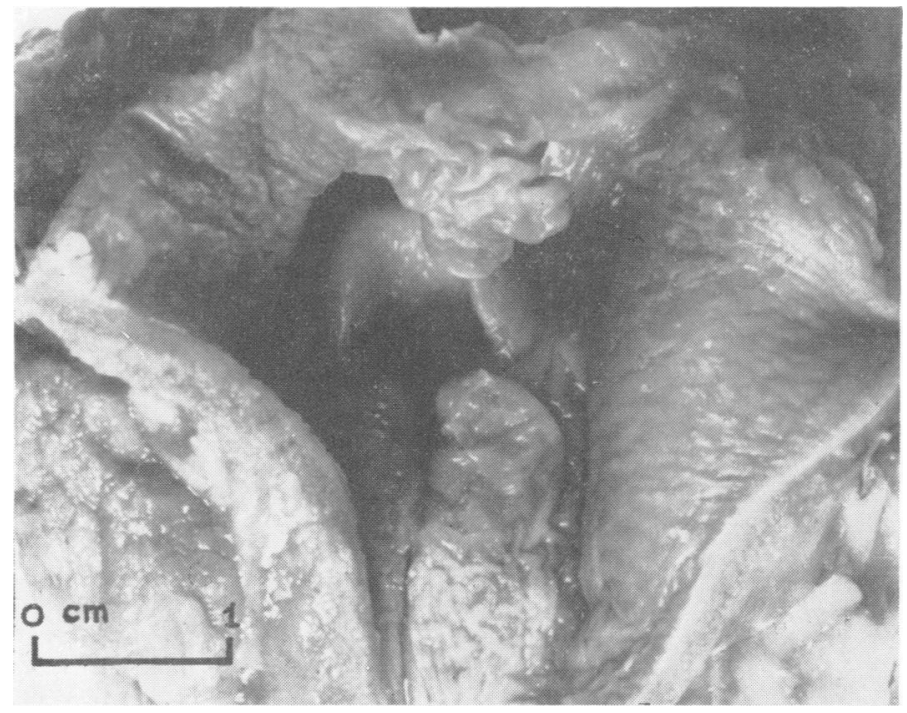

FIG. 4. Dissection of the pharynx, with the oesophagus opened up to reveal the bifid uvula above with soft palate otherwise complete. The norrnal epiglottis and opening into the larynx is in the centre of the photograph. seminiferous tubules but there were pus cells in the epididymis.

The brain was normal in size (weight 440 g.) but showed slight cerebral oedema with convolutional flattening. The olfactory tracts and trigones were absent and there was some irregularity of the convolutions of the rhinencephalon (Fig. 5) but no histological abnormality was noted. The olfactory bulbs were vestigial, being composed of undifferentiated nerve cells and were connected to the brain by a minute blood vessel only. The cribriform plate was small.

The only family history of congenital malformation is that a brother of the propositus' mother had one normal infant and one with an imperforate anus and accessory auricles (Fig. 6). This child is now apparently well after a successful operation. 


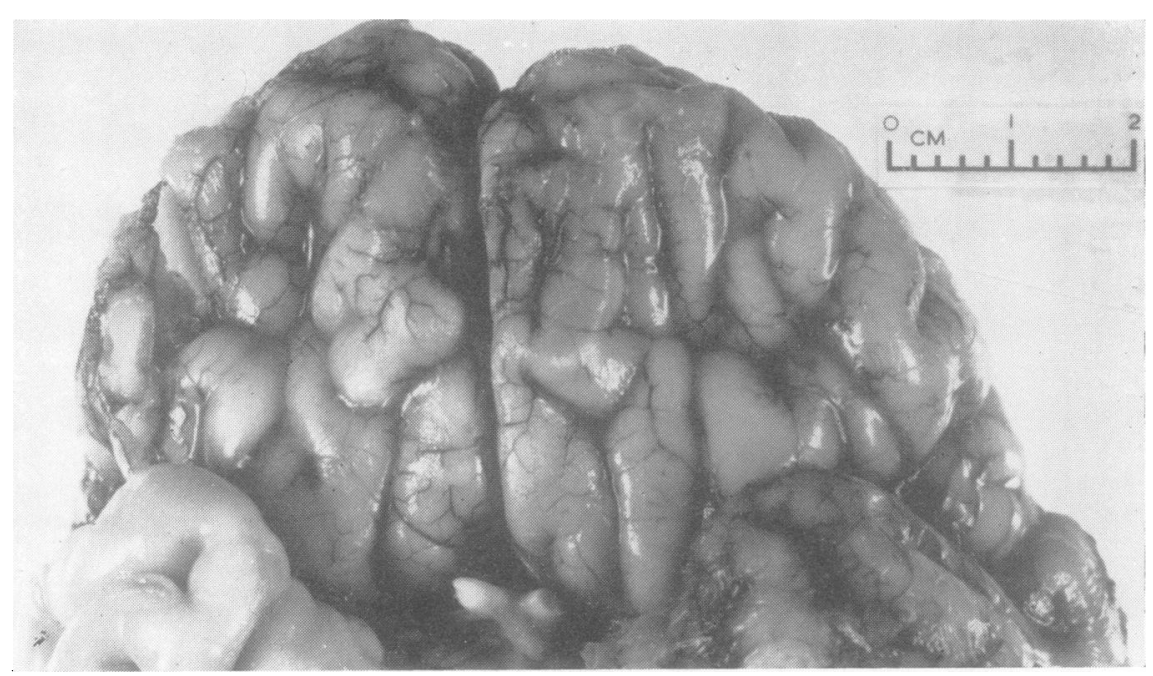

FIG. 5. Inferior view of the anterior portion of the cerebral hemispheres to show the absence of the olfactory tracts and trigones.

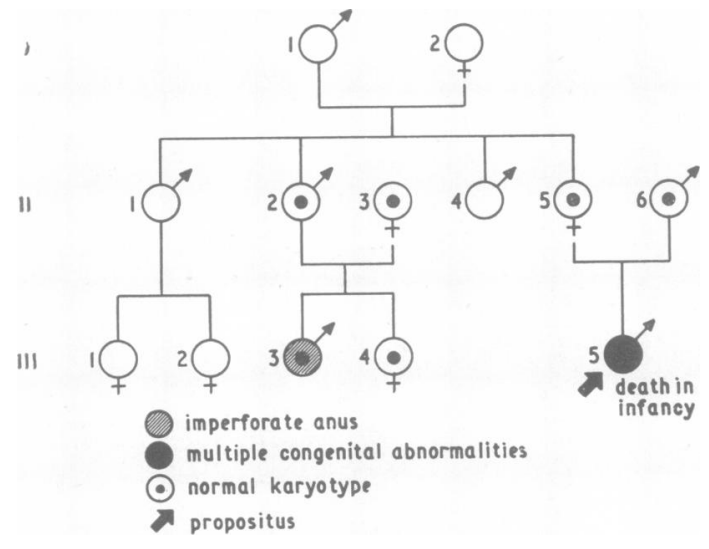

Fig. 6. Pedigree of family.
Chromosome Studies. Chromosome studies were carried out on cells obtained from a culture of skin taken at necropsy. 45 cells were counted and in 40 of these the chromosome number was 47 (Fig. 7). The extra chromosome in each cell was abnormal: in size, $\frac{\mathrm{Q}}{\mathbb{Q}}$ it was approximately equal to or slightly shorter than 0 a 2 I-22 chromosome, but it appeared to be slightly $\vec{O}$ more metacentric. In some cells, satellites were visible $Э$ on its short arms (Fig. 8) and it tended to associate with other satellited chromosomes.

Blood specimens were taken for chromosome studies from 6 other members of the family (II. $2,3,5$, and 6,3 and III. 3 and 4). In specimens taken from III. $40^{\circ}$ and III. 3 on two occasions, cells suitable for examination 3 were few (Table I), but those seen were examined in detail, and in none was the abnormal chromosomeo seen.

TABLE I

CYTOGENETIC RESULTS ON PART OF THE FAMILY

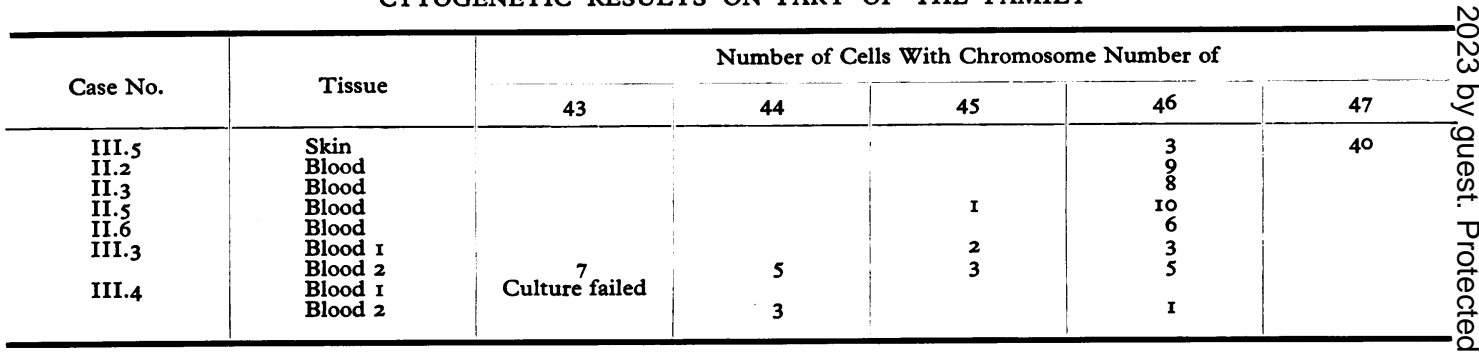




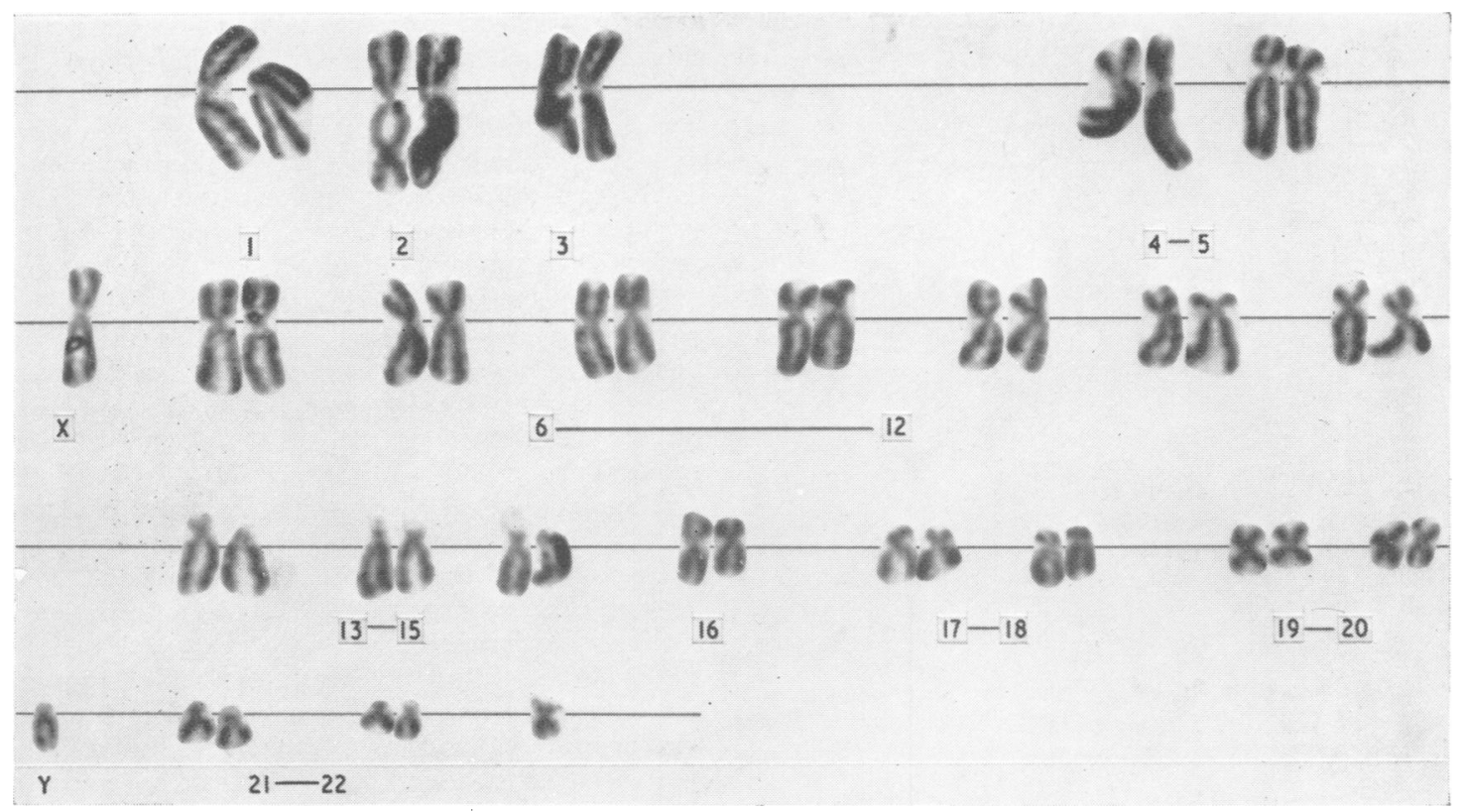

FIG. 7. Karyotype of III.5.

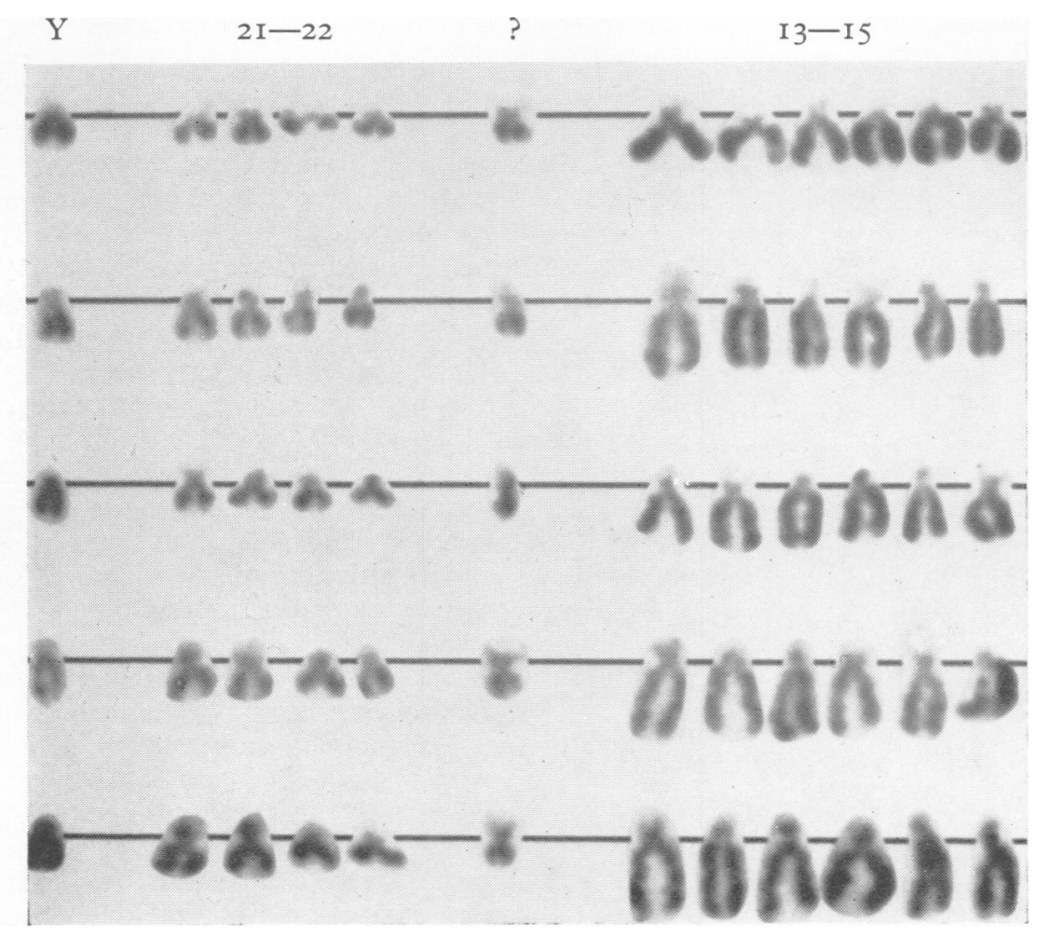

Fig. 8. Part of karyotype from 5 cells of III.5. 


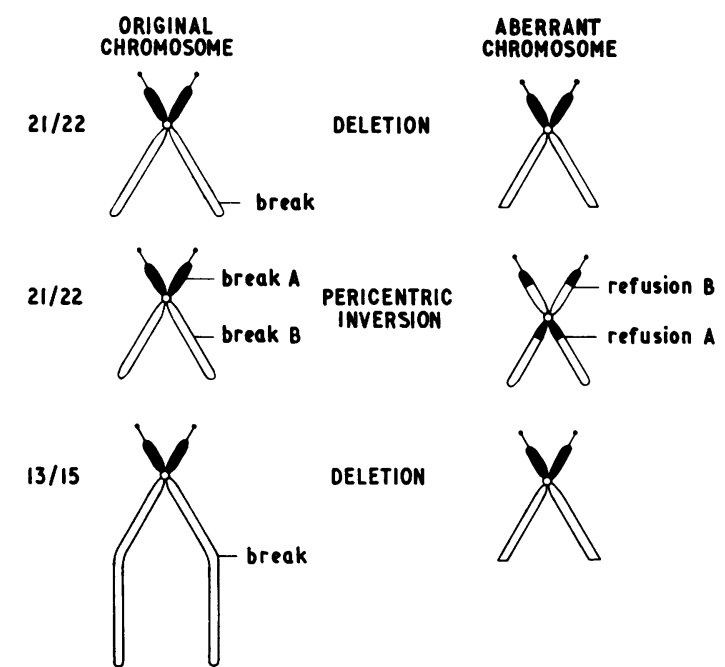

FIG. 9. Diagram to show possible origin of the aberrant chromosome.

\section{Discussion}

It is not possible to identify the extra chromosome material conclusively, but its probable origin, since it is satellited, is from an extra $2 I-22$ or $13-15$. Deletion of a small fragment of the long

TABLE II

COMPARISON OF THE FEATURES OF THE CASE WITH THOSE OF THE I3-15 AND 17-18 TRISOMIES

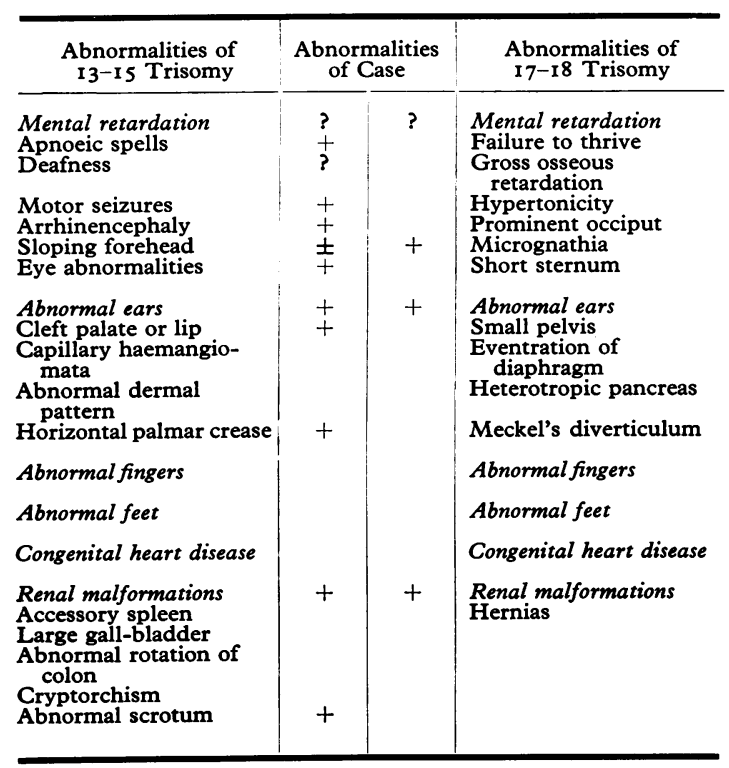

Features in italics are common to the majority of cases in both trisomies arms of a 2I-22 would produce a chromosomeब

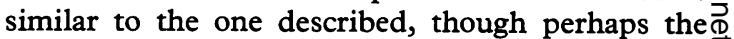
aberrant chromosome is too long for this. A? pericentric inversion would account for the mores metacentric appearance of the chromosome. Grosso deletion of the long arm of a 13-15, with loss of the acentric fragment, would also account for the abnormal chromosome (Fig. 9).

From a clinical point the three well-recognized autosomal trisomies have to be considered in ${ }^{\text {s }}$ this case. No specific syndrome has so far been. associated with trisomy 22, though a number of $\vec{\omega}$ cases have been reported (Hayward and Bower, $\omega$ 1960; Turner and Jennings, I96I; Dunn, Ford, $\overline{3}$ Auersperg, and Miller, 196I; Biesele, Schmid, 0 and Lawlis, 1962) with trisomy of the 21-22 group, i having none of the features of mongolism. The $\vec{\omega}$ present case appears to have no significant simi- $\omega$ larities with these cases.

No clinical or pathological features of mongo- lism were present, which seemed to eliminate $\subseteq$ incomplete trisomy 2r. However, it may not be impossible that that part of the chromosome, $\vec{\theta}$ which when present in the trisomic state is respon- $\mathscr{O}$ sible for the expression of mongolism, was the part that was deleted in this case (Ellis, Marshall, and Penrose, 1962).

Our patient shows some clinical and patho-흐 logical features of the $13-15$ and $17-18$ trisomy syndromes. As shown in Table II, the only® features of the $17-18$ trisomy found in the present $\overrightarrow{\vec{B}}$ case are those common to both trisomies, with the $\frac{3}{3}$ possible exception of micrognathia. This, which is a constant feature of the $17-18$ trisomy syndrome, has, however, been described in a number of undoubted cases of 13-15 trisomy (Lubs, Koenig and Brandt, I96I; Rosenfield, Breibart, Isaacs, $\dot{0}$ Klevit, and Mellman, 1962; Northcutt, 1962). It is of interest that one of the cases of Zellweger 0 et al. (1962), which was regarded as a partial trisomy of one of the chromosomes of the 13-15을 group, also had an imperforate anus and probably $\rightarrow$ an absent right kidney and ureter, as did a maternalo cousin with an imperforate anus.

It is concluded, therefore, that the abnormal of chromosome represents a gross deletion of an N additional 13-15 chromosome. Such an additional N chromosome could have arisen as a result of $\sigma$ non-disjunction and deletion. As the mother was young the usual increased tendency to nondisjunction of the satellited chromosomes with $\stackrel{\oplus}{\oplus}$ advanced maternal age does not apply. The most likely explanation of both deletion and 0 non-disjunction is that they occurred during $\vec{\otimes}$ meiosis when the paired chromosomes were $\frac{\Omega}{\mathbb{Q}}$ 
naturally breaking and rejoining during crossingover. Complex and unnatural twisting of arms could conceivably account for both events. That it is a phenomenon of gametogenesis and not of embryogenesis is supported by the apparent absence of mosaicism, though this has not been conclusively eliminated since only one tissue was examined.

\section{Summary}

A patient is described having some of the clinical manifestations of trisomy $13-15$ with arrhinencephaly, micropthalmia, micrognathos, abnormal ears, and accessory auricles, a bifid uvula, renal malformations, and an abnormal scrotum, with, in addition, an imperforate anus. The chromosome constitution of the patient is unique and the interpretation of the abnormality as a possible incomplete trisomy of a $13-15$ chromosome is discussed.

We wish to thank Mr T. J. Cooke, Mr N. J. Stark, and $\mathrm{Mr} \mathrm{J}$. O. Dew for technical assistance and the illustrations, and Dr A. Kertesz for bringing the case to our attention.

\section{REFERENCES}

Biesele, J. J., Schmid, W., and Lawlis, M. G. (1962). Mentally retarded schizoid twin girls with 47 chromosomes. Lancet, $\mathrm{I}, 403$.

Dent, T., Edwards, J. H., and Delhanty, J. D. A. (I963). A partial mongol. ibid., 2, 484 .

Dunn, H. G., Ford, D. K., Auersperg, N., and Miller, J. R. (196I). Benign congenital hypotonia with chromosomal anomaly. Pediatrics, 28, 578 .

Ellis, J. R., Marshall, R., and Penrose, L. S. (1962). An aberrant small acrocentric chromosome. Ann. hum. Genet., 26, 77.

Gustavson, K.-H., Hagberg, B., Finley, S. C., and Finley, W. H. (1962). An apparently identical extra autosome in two severely retarded sisters with multiple malformations. Cytogenetics, $1,32$.

Hayward, M. D., and Bower, B. D. (1960). Chromosomal trisomy associated with the Sturge-Weber syndrome. Lancet, 2, 844.

Lubs, H. A., Koenig, E. U., and Brandt, I. K. (196I). Trisomy 13-1 5: A clinical syndrome. ibid., 2, roor.

Northcutt, R. C. (1962). Multiple congenital anomalies in a negro infant with 13-15 trisomy. Sth. med. F. (Bgham, Ala.), 55, 385.

Patau, K., Therman, E., Inhorn, S. L., Smith, D. W., and Ruess, A. L. (196I). Partial-trisomy syndromes. II. An insertion as cause of the OFD syndrome in mother and daughter. Chromosoma (Berl.), 12, 573.

( Partial-trisomy syndromes. I. Sturge-Weber's disease. Amer. 7. hum. Genet., 13, 287.

Rosenfield, R. L., Breibart, S., Isaacs, H., Jr., Klevit, H. D., and Mellman, W. J. (1962). Trisomy of chromosomes 13-15 and 17-18: its association with infantile arteriosclerosis. Amer. $\mathcal{F}$. med. Sci., 244, 763 .

Turner, B., and Jennings, A. N. (I96I). Trisomy for chromosome 22. Lancet, 2, 49.

Zellweger, H., Mikamo, K., and Abbo, G. (1962). Two cases of multiple malformations with an autosomal chromosomal aberration - partial trisomy D? Helv. paediat. Acta, 17, 290. 